\title{
PERKEMBANGAN SEKSUAL SANTRI PADA PESANTREN SINGLE-SEX
}

\author{
Agus Abdul Rahman \\ Fakultas Psikologi UIN Sunan Gunung Djati Bandung
}

\begin{abstract}
Pesantren (Islamic boarding school) as islamic educational institution in general organizes and designs curriculum that able to avoid its students from sexual behavior that contrast to the islamic values, as well as in pesantren or after graduating from pesantren. One of the effort of pesntren to reach such goal among them are by organizing the relationship between sexs and to separate its students according to the sexs. Students are faced to the situation that different at all with the actual reality. Some aspects are regarded can direct to the social contact between sexs are controlled. The question appears about how the influence of the sexs separation (single sex-pesantren) to the student sexual development, as they coming out from that pesantren and must face the actual reality, which heterogenous, uncontrollabe and different at all with the relaity that experienced in pesantren.
\end{abstract}

Keyword: Sexual Development, single-sex

\section{Pendahuluan}

Globalisasi tampaknya sudah menjadi sesuatu keniscayaan. Siapapun sepertinya tidak bisa mengelak, dan tidak ada pilihan kecuali menerima dan menghadapinya. Perkembangan teknologi informasi dan komunikasi yang begitu pesat menjadikan globalisasi semakin nyata. Globalisasi membuat batas-batas antar negara menjadi relatif (borderless). Komunikasi antar negara menjadi mudah sehingga mendorong munculnya budaya global yang relatif homogen hampir di setiap negara.

Pada saat inilah, pertentangan budaya terjadi. Budaya lokal harus dominan karena dibantu oleh media elektronik dan diekspos pada setiap kesempatan. Suatu pertarungan yang tidak fair yang hasilnya akhirnya bisa diprediksi. Akhirnya budaya lokal mulai tergerus dan struktur sosial mulai mengalami perubahan. Perubahan inilah yang kemudian berpotensi menimbulkan disorganisasi sosial dan anomie (Soekanto, 1986).

Dalam konteks keindonesiaan, dampak disorganisasi sosial itu sudah sangat kentara. Masyarakat tampak seperti kehilangan identitas dirinya. Disharmoni sosial, konflik vertikal-horisontal, alienasi, narkotika, seks bebas, aborsi, korupsi, bunuh diri, kegilaan, tidak kekerasan, dan perceraian menjadi menu sarapan pagi yang tidak ada ujungnya. Bagi remaja, dampak disorganisasi sosial tersebut akan terasa lebih hebat lagi. Sebagai orang yang belum memiliki idetitas diri yang mantap dan kurang pengalaman, remaja akan menjadi mudah terpengaruh oleh nilai-nilai global yang lebih mengundang selera dan trend. Indikasinya bisa dilihat dari fakta-fakta berikut. 
Seksolog Boyke Dian Nugraha, memperkirakan angka aborsi di Indonesia berkisar antara 2,3 juta hingga 3 juta per tahunnya. Dari jumlah tersebut 50\% dilakukan oleh remaja (Berita Utama, 13 April, 2008). Fakta lain yang paling mutakhir disampaikan oleh komisi perlindungan anak. Survey terhadap pelajar SMP dan SMA di 33 propinsi menunjukkan bahwa 62,7 persennya sudah tidak perawan lagi (Pikiran rakyat, 11 Desember 2008). Hasil penelitian Annisa Foundation terhadap 412 responden dari 13 SMP dan SMU di Cianjur dan Cipanas selama bulan Juli hingga Desember 2006 menunjukkan bahwa 42,3 persen pelajar sudah hilang keperawanannya saat duduk di bangku sekolah (Sinar Indonesa Baru Online, 28 Maret 2007). Fakta lain, menurut Badan Narkotika Kota (BKN) Semarang terdapat 68 persen dari seluruh pengguna narkoba yang ada di kota Semarang berasal dari kalangan remaja. Hal itu tidak jauh berbeda dengan data yang disampaikan oleh psikiater Dadang Hawari bahwa 70 persen pasien pengguna narkotika yang ditanganinya termasuk remaja usia sekolah, baik yang duduk di bangku SMP, SMU, maupun Perguruan Tinggi.

$$
\text { Kenyataan ini tentu sangat }
$$
mengkhawatirkan, terutama bagi orang tua. Untuk itu, orang tua kemudian mengusahakan pendidikan yang terbaik bagi anak-anaknya, terutama pendidikan yang diduga akan bisa membentengi anak-anaknya dari perilakuperilaku menyimpang di atas. Lembaga pendidikan yang seringkali menjadi pilihan orang tua adalah pesantren. Orang tua mempunyai keyakinan bahwa pesantren akan dapat menjaga anak-anaknya dari perilaku menyimpang.

Harapan masyarakat tersebut tampaknya tidak berlebihan. Pesantren sebagai lembaga pendidikan Islam memang didirikan untuk menjaga moral masyarakat. Pesantren didesain sedemikian rupa sehingga diharapkan bisa melahirkan santri-santri yang memiliki keyakinan teologis yang mantap dan berakhlakul karimah. Hasil penelitian Jeynes dan Martinez (2007), menunjukkan bahwa sekolah berbasis agama memang mempunyai kemampuan untuk meminimalisir kenakalan remaja dan penggunaan obat-obat terlarang. Lebih lanjut Jeynes (2003) mengatakan :

"religious schools and/or
religious commitment are
associated with higher levels of
academic achievement, a reduced
gap between white and minority
students as well as wealthy and
poor students, more productive
kinds of school behavior, greater
involvement in learning, greater
racial harmony, less violence, less
use of drugs and alcohol,"

(sekolah agama dan atau komitmen beragama berhubungan dengan tingginya prestasi akademik, menurunya gap antara siswa kulit putih dan kaum minoritas juga gap antara siswa yang kaya dan miskin, munculnya perilaku siswa yang lebih produktif, partisipasi yang lebih besar pada proses belajar, menurunnya rasialisme dan kekerasan, serta menurunnya penggunaan narkotika)

Fakta tersebut menunjukkan bahwa sekolah berbasis agama (baca : pesantren) tampak cukup positif di dalam menjaga 
perilaku remaja dari perilaku menyimpang seperti agresi, penggunaan narkotika, kenakalan remaja, ataupun rasialisme. Lalu, bagaimana pengaruh pesantren terhadap perilaku seksual?

Islam mengatur setiap aspek kehidupan manusia, termasuk perilaku seksual. Pesantren sebagai lembaga pendidikan Islam mau tidak mau harus mengatur dan mendesain kurikulum yang bisa menghindarkan santri-santrinya dari perilaku seksual yang bertentangan dengan nilai-nilai Islam, baik sewaktu di pesantren maupun setelah keluar dari pesantren. Salah satu upaya pesantren untuk mencapai tujuan tersebut antara lain dengan mengatur relasi antar jenis kelamin dan atau memisahkan santri-santrinya berdasarkan jenis kelamin. Berikut sebagian bentuk-bentuk pengaturan relasi antara santri putra dan santri putri yang didasarkan pada ayat al-Qur'an dan hadits yang mengatur hubungan antara laki-laki dan perempuan.

a. Mewajibkan santri-santrinya untuk menutup aurat. Dasarnya antara lain firman Allah Swt yang berbunyi : “... hendaklah mereka tutupkan kerudung (telekung) mereka ke kuduk dan dada mereka, dan janganlah mereka memperlihatkan perhiasan mereka ..." (Q.S. Annur : 31) dan Q.S. Al A'raaf : 26 yakni :

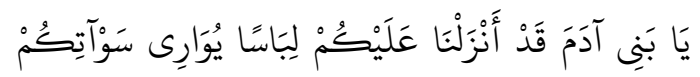

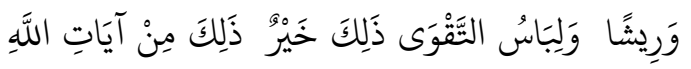

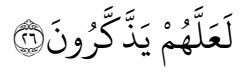

"Hai anak Adam, sesungguhnya Kami telah menurunkan kepadamu pakaian untuk menutupi ‘auratmu dan pakaian indah untuk perhiasan. Dan pakaian takwa itulah yang paling baik. Yang demikian itu adalah sebahagian dari tanda-tanda kekuasaan Allah, mudahmudahan mereka selalu ingat"

b. Melarang ikhtilath antara santri putra dan santri putri. Dasarnya antara lain hadits Nabi yang diriwayatkan oleh Abdullah bin Abbas ra. yang menyatakan bahwa ia pernah mendengar Rasulullah Saw. ceramah dengan mengatakan : “jangan sekali-kali seorang lelaki berdua-duaan dengan seorang wanita, kecuali disertai mahramnya".

c. Membatasi komunikasi (baca : kontak mata). Santri putra dan santri putri diatur sedemikian rupa sehingga tidak mempunyai kesempatan untuk kontak mata secara intens. Dasarnya antara lain adalah firman Allah Swt. yang berbunya : "katakanlah kepada orang laki-laki yang beriman: 'hendaklah mereka menahan pandangannya dan memelihara kemaluannya' (Q.S. Annur : 30). Dasar yang lain adalah sabda Nabi yang diriwayatkan oleh Abu Hurairah yang berbunyi : "zina kedua mata adalah memandang".

d. Melarang santri-santrinya untuk bersentuhan dengan orang yang bukan mahramnya, termasuk berjabat tangan. Dasarnya antara lain hadits nabi yang diriwayatkan oleh Ma'qil bin Yasar yang berbunyi : "seseorang di antara kalian ditusuk jarum besi di kepalanya lebih baik 
daripada bersentuhan dengan wanita yang bukan mahramnya."

e. Melarang santri-santrinya berpacaran. Larangan ini didasarkan pada karakteristik pacaran itu sendiri yang betentangan dengan nilai-nilai islam. Antara lain ada unsur ikhtilath, saling berpandangan, dan saling bersentuhan. Dasar yang lain adalah karena berpacaran sebagai komplek yang mengandung unsur-unsur yang sudah disebutkan maka berpacaran seringkali dianggap sebagai jalan menuju perzinahan. Padahal, dalam Islam, jangankan melakukan, mendekatinya pun dilarang

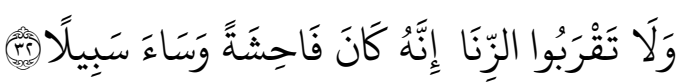
"Dan janganlah kamu mendekati zina; sesungguhnya zina itu adalah suatu perbuatan yang keji dan suatu jalan yang buruk” (QS. Al Israa; 32).

f. Memisahkan antara santri putra dan santri putri. Aturan lain yang diterapkan oleh kebanyakan pesantren adalah memisahkan komplek santri putra dan santri putri. Aturan ini diterapkan untuk mencegah dan membatasi santri dari relasi jenis kelamin yang bertentangan dengan nilai-nilai Islam.

Dari upaya-upaya tersebut, tampak yang paling ekstrim dan menarik adalah upaya pesantren memisahkan santri berdasarkan jenis kelaminnya. Santri putra dipisahkan dari santri putri, baik di asrama ataupun kelas. Santri putri hanya boleh berhubungan dan kontaks sosial dengan sesama jenisnya, dan begitu sebaliknya. Hal ini menarik karena seperti situasi eksperimental. Santri dihadapkan pada situasi yang sama sekali berbeda dengan realitas yang sebenarnya. Beberapa aspek yang diduga akan mengarahkan pada kontak sosial antar jenis kelamin dikendalikan atau dikontrol. Efek jangka pendeknya memang santri menjadi sangat steril dari perilaku seksual yang tidak diharapkan (pre-marital sexual behavior). Selama dalam pesantren dan masih berhubungan dengan orang-orang yang memiliki latar belakang yang sama, santri tidak akan banyak mengalami masalah seksualitas. Pertanyaannya adalah bagaimana ketika santri keluar dari pesantren dan harus menghadapi realitas sesungguhnya, yang heterogen, tidak terkontrol dan sama sekali berbeda dengan realitas yang selama ini dialami di pesantren. Bagaimana pengaruh pemisahan berdasarkan jenis kelamin tersebut (single-sex pesantren) terhadap perkembangan seksual santri? Hal ini merupakan problem generalisasi. Suatu problem yang seringkali menjadi isu pada model-model eksperimental.

\section{Model Pesantren}

Menurut Ziemek (dalam Mujahidin, 2005), kata pesantren terdiri dari kata "santri" yang memiliki awalan "pe" dan akhiran "an" yang menunjukkan tempat. Sedangkan "santri" merupakan singkatan dari kata "sant" yang berarti manusia baik dan "tra" yang berarti suka menolong. Jadi, pesantren berarti tempat pendidikan manusia baik-baik. Santri, menurut Geertz seperti dikutip Ziemek (dalam Mujahidin 2005) mempunyai arti luas dan 
sempit. Secara sempit, santri berarti seorang pelajar sekolah agama, yang disebut pesantren, sedangkan secara luas, kata santri mengacu pada seorang anggota bagian penduduk jawa yang menganut Islam dengan sungguhsungguh.

Sebagai lembaga pendidikan yang khas Indonesia, pesantren memiliki ciri-ciri khas yang tidak dimiliki oleh model pendidikan lainnya. Djaelani (dalam Noor, 2006) menyebutkan 5 ciri khas pesantren :

- Seorang kyai sebagai pimpinan pesantren

- Santri yang bermukim di asrama dan belajar pada kyai

- Asrama sebagai tempat tinggal para santri

- Pengajian sebagai bentuk pengajaran dan;

- Mesjid sebagai pusat kegiatan pondok pesantren.

Mujahidin (2005) menyebutkan ciri-ciri khas dari pesantren yang tidak didapati di model pendidikan yang lain.

a. Pola interaksi kyai dan santri : hubungan akrab, santri taat dan patuh pada kyai, santri hidup mandiri dan sederhana, semangat gotong royong dalam suasa penuh persaudaraan, hidup berdisiplin dan tirakat.

b. Prinsip-prinsip pembelajaran : bersifat theosentis, sukarela dan mengabdi, kearifan, kesederhanaan, kolektivitas, mengatur kegiatan bersama, mandiri, kebebasan terpimpin, mencari ilmu dan mengabdi, mengamalkan ajaran agama, tanpa ijazah, restu kyai.

c. Metode dan teknik pembelajaran: sorogan, bandongan/wetonen, hafalan, musyawarah/mudzakarah, talaran.

Seiring dengan perkembangan jaman, pesantren kemudian melakukan adaptasi dan modifikasi dalam berbagai aspek. Maka, dewasa ini suatu lembaga pendidikan mungkin saja menamakan dirinya sebagai pesantren, walaupun tidak memenuhi ciri-ciri di atas. Dalam perkembangannya, bentuk pendidikan pesantren bisa diklasifikasikan menjadi 4 bentuk (Arifin, dalam Mujahidin, 2005).

a. Pesantren Salafi (Tradisional), yaitu pesantren yang hanya memberikan materi agama kepada para santrinya. Tujuan pokok dari pesantren ini adalah mencetak kader-kader yang akan menyebarkan Islam di tengah masyarakatnya.

b. Pesantren Ribathi, yaitu pesantren yang mengkombinasikan pemberian materi agama dengan materi umum. Biasanya, selain tempat pengajian, pada pesantren ini disediakan pendidikan formal yang dapat ditempuh oleh santrinya.

c. Pesantren Khalafi (modern), yaitu pesantren yang didesain dengan kurikulum yang disusun secara baik untuk mencapai tujuan yang diinginkan. Disebut khalafi karena adanya berbagai perubahan yang dilakukan baik pada metode maupun materi pembelajaran. Para santri tidak hanya diberikan materi agama dan umum, tetapi juga berbagai materi yang berkaitan dengan skill atau vocational. 
d. Pesantren Jami'i (asrama pelajar dan mahasiswa), yaitu pesantren yang memberikan pengajian kepada pelajar atau mahasiswa sebagai suplemen bagi mereka.

Selain itu, berdasarkan jenis kelamin santri-santrinya, pesantren bisa dibedakan menjadi dua. Ada pesantren yang santrinya terdiri dari laki-laki dan perempuan (pesantren co-educational), dan ada pesantren yang hanya terdiri dari santri putri saja atau putra saja (pesantren single-sex). Pemilihan model pendidikan pesantren seperti itu (coeducational atau single-sex) tidak terlepas dari pemahaman atau interpretasi kyai terhadap ayat atau hadits yang mengatur hubungan antara laki-laki dan perempuan.

\section{Pengaruh Pesantren Single-Sex Terhadap Perkembangan Seksual Santri}

Kebutuhan seksual merupakan kebutuhan yang tidak terelakkan. Siapapun tidak bisa menghindar dari kebutuhan tersebut. Kebutuhan seksual tidak bisa ditekan atau dihilangkan. Jika kebutuhan tersebut tidak dipenuhi dengan baik, maka siapapun akan bisa mengalami kondisi dis-equilibrium atau ketidakseimbangan psikologis yang efeknya akan sangat beragam.

Namun demikian, kebutuhan seksual pun bukanlah kebutuhan yang harus diikuti tanpa batas. Ada fitrah manusiawi atau hukum psikologis yang menyarankan kebutuhan seksual itu sebaiknya dikendalikan. Frankl (1967) mengatakan, ketika mengkritik prinsip kesenangan dari Freud, bahwa semakin kesenangan itu dikejar, maka yang didapatkan bukanlah kepuasaan, akan tetapi ketidakpuasaan. Artinya, semakin kesenangan seksual itu diikuti, maka yang didapat justru adalah semakin besarnya keinginan untuk mendapatkan kesenangan seksual berikutnya yang lebih besar. Efek negatif berikutnya adalah jika kekuatan keinginan tersebut sudah begitu besar, maka suatu saat akan sampai pada satu titik di mana kebutuhan seksual itulah yang mengendalikan manusia, bukan akal atau ketakwaannya.

Adapun potensi manusia untuk mengendalikan kebutuhan seksualnya sebenarnya bukan masalah. Manusia diciptakan bukanlah sebagai korban dari kebutuhan-kebutuhan yang melekat dalam diri eksistensialnya. Sebagai makhluk yang berakal, hayawan natiq, manusia diciptakan lengkap dengan potensi untuk dapat melakukan transendensi diri (self transcendence) atau mengambil jarak baik terhadap dirinya sendiri maupun terhadap lingkungannya. Manusia mempunyai kekuasaan untuk menilai, mengatur, dan mengendalikan kebutuhankebutuhannya sebaik mungkin, termasuk mengatur kebutuhan seksualnya( Frankl, 1967).

Dalam konteks ini, Islam menawarkan aturan main yang cukup detail untuk mengatur dan mengendalikan kebutuhan seksual yang melekat pada diri eksistensial manusia. Islam menjelaskan aturan-aturan mengenai hubungan lelaki-perempuan yang dibolehkan dan tidak dibolehkan (Q.S. Al-Israa; 32). Islam mengatur aurat laki-laki dan perempuan. Islam menetapkan syariat munakahah serta sangsi 
terhadap pelanggaran-pelanggaran (Q.S. Annisa: 3; Q.S. Annur: 2)

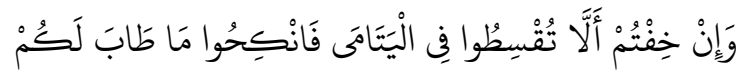

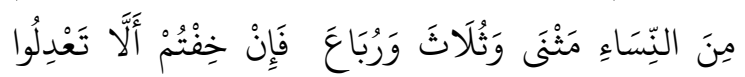

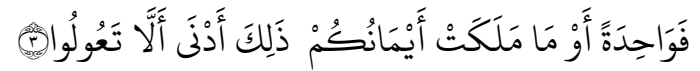

"Dan jika kamu takut tidak akan dapat berlaku adil terhadap (hak-hak) perempuan yatim (bilamana kamu mengawininya), maka kawinilah wanita-wanita (lain) yang kamu senangi: dua, tiga atau empat. Kemudian jika kamu takut tidak akan dapat berlaku adil, maka (kawinilah) seorang saja, atau budakbudak yang kamu miliki. Yang demikian itu adalah lebih dekat kepada tidak berbuat aniaya” (Q.S. Annisa: 3).

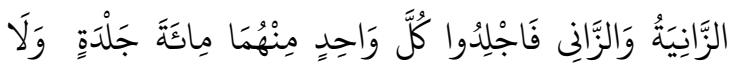

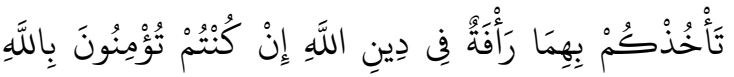

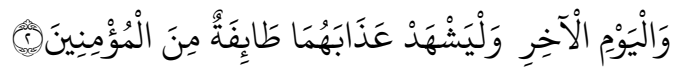

"Perempuan yang berzina dan laki-laki yang berzina, maka deralah tiap-tiap seorang dari keduanya seratus kali dera, dan janganlah belas kasihan kepada keduanya mencegah kamu untuk (menjalankan) agama Allah, jika kamu beriman kepada Allah, dan hari akhirat, dan hendaklah (pelaksanaan) hukuman mereka disaksikan oleh sekumpulan dari orang-orang yang beriman" (QS. Annur : 2)

Aturan main itu kemudian dioperasionalisasikan juga dalam pesantren, salah satunya dengan pemilihan model pesantren single-sex dan mengatur secara ketat hubungan antar jenis kelamin. Di pesantren single-sex, santri tidak hanya belajar pengetahuan agama, belajar bersikap dan beramal, akan tetapi juga dikondisikan dan dijauhkan dari rangsang-rangsang perilaku seksual yang berpotensi dosa. Santri betulbetul dihadapkan pada situasi eksperimental yang terkontrol dan pastinya berbeda dengan realitas sosial yang sesungguhnya.

Perbedaan struktur dan pola hubungan antar jenis kelamin di pesantren dan realitas sosial yang sesungguhnya tentu mempunyai pengaruh yang berbeda terhadap pemenuhan tugas-tugas perkembangan santri. Di luar negeri, penelitian mengenai pengaruh singlesex schooling dan co-educational schooling terhadap kepribadian sudah banyak dilakukan. Mahoney, Granslee \& Joseph, Astin, dan Haag (dalam Ferney \& Domingue, 2006) secara umum menunjukkan bahwa ada perbedaan karakteristik antara siswa yang sekolah dengan menggunakan sistem co-educational dan single-sex. Perbedaan tersebut antara lain dalam hal physical space, linguistic space, kekritisan terhadap perilaku sendiri, tampilan fisik, agresivitas verbal, keterlibatan akademik, dan intensitas interaksi. Selain itu, penelitian Astin, Carpenter, Lee dan Bryk (dalam, Datnow dan Hubbard, 2002) menunjukkan bahwa siswa pada sekolah single sex lebih unggul dalam prestasi dan self esteem.

Sistem single-sex ataupun coeducational tampaknya juga akan berpengaruh pada perkembangan seksual santri. Sebab, menurut Lerner dan Spanier (dalam Moore \& Rosenthal, 1993), walaupun perkembangan seksual atau sexual socialization bersifat life long process, tapi menurutnya yang paling penting terjadi pada masa remaja. Pada masa remaja ini, beberapa perubahan penting baik secara fisik, kognitif, sosial, ataupun emosional terjadi secara serentak. Karena penting, maka perkembangan seksual remaja akan 
berpengaruh terhadap perkembangan seksual di masa-masa berikutnya.

Untuk lebih memahami bagaimana potensi pengaruh single-sex ataupun coeducational terhadap perkembangan seksual santri, ada baiknya disampaikan tugas-tugas perkembangan seksual dari Lerner \& Spanier dan Hurlock. Menurut Lerner dan Spanier (dalam Moore \& Rosenthal, 1993), “job description" atau tugas perkembangan seksual remaja adalah : mengembangkan ketertarikan pada objek-objek seks; memiliki identitas gender (gender identity), mengembangkan kemampuan melakukan peran-peran sekual (sex roles), belajar memahami perilaku seksual; memperoleh keterampilan, pengetahuan, dan nilai-nilai yang berhubungan dengan seks; serta mampu menunjukkan perilaku seksual yang sesuai dengan harapan kultural dan konteks. Menurut Hurlock (1980), salah satu tugas perkembangan remaja (baca : santri) adalah pembentukan hubungan-hubungan baru yang lebih matang dengan lawan jenis dan memainkan peran yang tepat dengan seksnya.

$$
\text { Prinsipnya, ketika tugas }
$$

perkembangan tersebut tidak terpenuhi dengan wajar, maka akan muncul efek-efek yang tidak menguntungkan. Maka, berdasarkan potensi terpenuhi atau tidak terpenuhinya tugas-tugas perkembangan seksual tersebut tampak bahwa santri dari pesantren single sex akan cenderung mengalami hambatan perkembangan seksual dibanding santri dari pesantren co-educational. Adapun bentuk-bentuk hambatannya akan sangat beragam tergantung dari banyak faktor.
Sebagiannya antara lain : kurang bisa mengekpresikan perasaan suka pada lawan jenis; mempunyai persepsi negatif terhadap lawan jenis; mengalami kecemasan terhadap keintiman, kurang trampil mengendalikan perasaan dan hasrat seksual; over-sensitif atau undersensitif terhadap objek-objek yang berbau seks; kurang trampil memerankan peran-peran seksual; atau mengalami kesulitan ketika melakukan relasi sosial dengan lawan jenis. Berbeda dengan santri dari pesantren single-sex, santri dari pesantren co-educational diduga akan memiliki karakteristik dan perilaku seksual yang lebih profer. Hal ini diungkapkan oleh Jackie M. Blount (2005), bahwa "co-education would help children become properly heterosexual and develop gender-appropriate behavior and characteristics". Mullins (2005) pun menjelaskan bahwa kesempatan untuk melakukan role modeling akan lebih besar pada single-sex schooling.

Masalah-masalah tersebut akan tampak jelas terutama ketika santri harus berhadap-hadapan dengan realitas sosial yang sesungguhnya, yaitu realitas yang struktur dan pola hubungan antar jenis kelaminnya berbeda bahkan paradoks dengan realitas yang pernah dialaminya. Semakin tinggi gap diantara kedua realitas tersebut, maka semakin besar potensi culture-shock dan hambatan penyesuaian sosial yang mungkin dialami santri. Bagaimana santri mengatasi potensi culture-shock dan hambatan penyesuaian sosial ini akan ditentukan oleh banyak hal. Begitu juga, apakah culture-shock dan hambatan penyesuaian sosial akan 
mengarahkan santri untuk melakukan perilaku seksual pranikah atau tidak, juga ditentukan oleh banyak hal.

Salah satu faktor yang diduga akan berpengaruh besar terhadap perilaku seksual santri ketika keluar dari pesantren adalah kominten keberagamaan. Yang dimaksud komitmen beragamaan tentunya bukan hanya keluasan pengetahuaan mengenai agama, tapi juga termasuk penghayatan dan pengamalan nilai-nilai agama. Dalam banyak penelitian menunjukan adanya korelasi negatif antara komitmen keberagamaan dan perilaku seksual pranikah. Jeynes dan Martinez (2007) menegaskan bahwa komitmen beragama berhubungan dengan menurunya pre-marital intercourse. Beberapa penelitian lain menunjukkan bahwa komitmen beragama berhubungan dengan rendahnya perilaku seksual pra-nikah dan kehamilan di luar nikah (Jeynes, 2003; Spilka, Hood, Hunsberger, \& Gorsuch, 2003).

\section{Daftar Pustaka}

Canary, Emmers-Sommer. (1997). Sex and Gender Differences in Personal Relationships. The guilford Press. USA

Datnow Amanda, H.L. (2002). Gender in Policy and Practice: Perspectives on Single-sex and Coeducational. Routledge. Taylor \& Francis Group

Ferney \& Domingue. (2006). (1 April 2007). The Relationship between Type of Schooling (Single-Sex VS CoEducational) and Gender roles. http://www.ed.gov/rschstat/eval/other/si ngle-sex/index.html

Frankl, VE. (1967). Psychotherapy and Existentialism. New York. Washington Squre Press
Hurlock, EB. (1980). Psikologi Perkembangan : Suatu Pendekatan Sepanjang Rentang Kehidupan. Erlangga. Jakarta.

Jeynes William, Martinez Enedina. (2007). Christianity, Education, and Modern Society. Information Age Publishing. Inc.

Jeynes, William. (2003). Religion, Education, and Academic Success. Information Age Publishing. Inc.

Mujahidin, E. (2005). Pesantren Kilat : Alternatif Pendidikan Agama di Luar Sekolah. Jakarta. Pustaka Al Kautsar.

Mullins, Andrew. (2005). (5 April 2007). Comparing the benefits of single-sex education and coeducation. http://www.mercatornet.com/

Noor, M. (2006). Potret Dunia Pesantren. Humaniora. Bandung

Pikiran Rakyat (11 Desember 2008). 62.7 Persen Siswi SMP dan SMA tidak Perawan.

Sarwono, S.W. (1997). Apakah Seks itu? Petunjuk bagi Remaja. Jakarta: Bekerja sama dengan Perkumpulan Keluarga Berencana

Sinar Indonesia Baru Online (28 Maret 2007). Memprihatinkan, 42,3 persen Pelajar Cianjur telah Berhubungan Seks Pranikah.

Soekanto, S., (1986). Sosiologi Suatu Pengantar. Jakarta. CV. Rajawali

Spilka Bernard, Hood Ralph W.,Hunsberger Jr., Bruce, Gorsuch Richard. (2003). The Psychology of Religion: An Empirical Approach. $\quad$ Guilford Press 
Psympathic, Vol. I, No.1, 2008: 47 - 56 